\title{
(RE)PENSANDO O DIREITO: A NECESSIDADE DE TEORIAS FEMINISTAS DO
} DIREITO NO ENSINO JURÍDICO

(RE)THINKING THE LAW: THE NECESSITY OF FEMINIST JURISPRUDENCE IN LEGAL

\author{
EDUCATION
}

\author{
Anna Marcella Mendes Garcia* \\ Camyla Galeão de Azevedo**
}

\section{RESUMO}

O objetivo deste trabalho é demonstrar que o Direito foi construído com base no olhar masculino, o que colocou a mulher em posição secundária e estigmatizada no ordenamento jurídico pátrio. As teorias feministas do Direito surgem como uma proposta de emancipação das mulheres e do Direito, reconstruindo suas bases de maneira mais igualitária. Trata-se de pesquisa bibliográfica, pautada no método hipotético-dedutivo, que parte da hipótese de que o Direito é uma ciência androcêntrica, para concluir que a teoria mais adequada para desconstituir esta realidade seria a feminista, tendo como principal referencial teórico a obra Teorías Jurídicas Feministas, de Rosa Ricoy.

Palavras-chave: Ensino jurídico. Teorias feministas do direito. Teoria do direito. Feminismos.

\begin{abstract}
The aim of this work is to demonstrate that the law was built based on the masculine gaze, which placed women in a secondary and stigmatized position in the legal order. Feminist jurisprudence emerge as a proposal to emancipate women and the law, rebuilding their foundations in a more egalitarian way. It is a bibliographical research, based on the hypothetical-deductive method, that starts from the hypothesis that the Law is an androcentric science, to conclude that the most adequate theory to deconstitute this reality would be feminist, having as theoretical reference the work Teorías Jurídicas Feministas by Rosa Ricoy.
\end{abstract}

Keywords: Legal education. Feminist jurisprudence. Jurisprudence. Feminisms.

\footnotetext{
* Mestranda em Direitos Humanos pela Universidade Federal do Pará - PPGD/UFPA, com bolsa da Coordenação de Aperfeiçoamento de Pessoal de Nível Superior (CAPES). Especialista em Direito Processual. Advogada. Email: marcellamendesgarcia@gmail.com.

** Mestranda em Direito, Políticas Públicas e Desenvolvimento Regional pelo Centro Universitário do Pará CESUPA. Advogada. Coordenadora do Grupo Democracia e Feminismos, vinculado à LAJUPA. E-mail: camylagaleao.a@hotmail.com.
} 


\section{INTRODUÇÃO}

O homem está no centro de todas as instituições modernas - Igreja, família, Estado, etc — sendo o principal responsável por sua criação e regular desenvolvimento. É sob o olhar deste homem, normalmente branco, de meia idade e pertencente à elite, com influência social e poder aquisitivo, e representando seus interesses, que as instituições foram criadas e são mantidas até hoje.

Isso se deu porque durante séculos a educação, a política e o espaço público como um todo foram setores destinados exclusivamente a esse modelo de homem acima citado, de modo que somente ele tinha acesso a todos os privilégios que eles poderiam proporcionar, o que influenciou diretamente nas estruturas de tais espaços.

Esse homem também foi o responsável por criar o Direito vigente, pelos mesmos motivos, tendo servido como referência de universalidade para o mesmo, enquanto que todos os outros indivíduos - mulheres, negros, índios, crianças - não possuíam influência no ordenamento jurídico, sendo tutelados a partir da visão masculina sobre eles (SOUSA, 2014, p. 9).

Obviamente tal visão era restritiva e excludente, uma vez que partia de um único sujeito referencial, valorizando somente suas necessidades e atendendo exclusivamente aos seus objetivos, o que prejudicou sobremaneira os grupos sem representatividade até então, colocando-os à margem da sociedade e do Direito.

O presente trabalho parte da premissa de que o Direito é uma ciência criada por e para homens, o que fez com que se tornasse excludente, particularmente em relação às mulheres. Com base na pesquisa bibliográfica, cujo principal referencial teórico é a obra Teorías Jurídicas Feministas, de Rosa Ricoy, a partir do método hipotético-dedutivo, buscar-se-á responder ao problema de pesquisa, que se perfaz no questionamento acerca de quais teorias seriam, então, na atualidade, as mais adequadas enquanto fundamentação jusfilosófica do Direito.

O artigo estruturar-se-á em quatro seções principais, sendo a primeira delas destinada a introduzir o tema, problema de pesquisa, referencial teórico e metodologia utilizados; a segunda, conceitual, para situar o leitor sobre o que são as teorias feministas do Direito e apresentar algumas delas, selecionadas dentre as que consideramos mais pertinentes para o ensino jurídico; a terceira para confirmar a hipótese de o Direito é uma ciência androcêntrica e que, por isso, se faz necessária a adoção e ensino de teorias feministas neste ramo do saber, 
respondendo ao problema de pesquisa; e última para tecer algumas considerações finais a respeito do tema.

\section{TEORIAS FEMINISTAS DO DIREITO}

No âmbito da separação entre o público e o privado, as mulheres estiveram, ao longo de séculos, estritamente reclusas ao lar, enquanto os homens eram livres para transitar entre a política e o âmbito privado. Neste sentido, as mulheres possuem o papel de emancipadoras dos homens, pois, com o exercício de suas tradicionais atribuições, vinculadas ao cuidar, permitem que eles se emancipem de suas relações privadas e adentrem no mundo público para exercer o que seria o seu trabalho natural. Dessa feita, foram os homens que criaram as principais instituições que permanecem na atualidade, como o Estado e o Direito, dada a impossibilidade das mulheres participarem destes processos.

Entretanto, mesmo que emancipados do âmbito privado e da casa, eles mantêm o comando do âmbito público e do lar privado, pois são os responsáveis por comandar a máquina patriarcal. Isso se dá pela construção histórico-social ocidental que vincula o homem à força, inteligência e poder; já a mulher, à pureza, docilidade e servidão.

Diante deste cenário, em que as mulheres foram, durante muito tempo, impossibilitadas de acessar o espaço público e tudo a ele inerente, coube aos homens fundar as estruturas das sociedades modernas, o que inclui a ciência jurídica.

Sobre a influência masculina nas instituições sociais, incluindo o Direito, Rita Sousa (2014, p. 9) afirma:

No centro ontológico das instituições modernas está um sujeito em torno do qual foi constituída e ordenada a realidade: o sujeito masculino. $\mathrm{O}$ direito posto não deixou de incorporar este facto. Expressão das dinâmicas sociais, também no direito o universal e o referente era o homem, e a mulher o especial e o derivado.

Um exemplo do masculino como universal é a Declaração dos Direitos do Homem e do Cidadão, de 1789, que deveria se dirigir a todas as pessoas, mas desde seu título retratava fielmente o paradigma dominante a quando da Revolução Francesa: a "iluminação" de fato pertencia somente aos homens. Isto porque a educação era exclusividade deles e, consequentemente, o domínio sobre o saber científico, o que impossibilitava as mulheres de adentrarem neste campo. 
A linguagem do Direito diz muito a respeito de quem é seu protagonista. Ela não utiliza o masculino como sinônimo de neutralidade como pretende fazer parecer, e sim retrata o real destinatário e produtor das normas. Sobre esta característica presente em vários ordenamentos jurídicos, mas, em particular, no português:

O homem foi, portanto, o único sujeito que as leis se destinavam proteger, facto que é tão evidenciado pelo seu conteúdo substantivo como pela própria linguagem da lei. «Só o homem é susceptível de direitos e obrigações», declarava o artigo 1.o do Código de Seabra, indiferente ao facto de, pelo seu sentido literal, as mulheres não terem representação, e indiferente, ainda, ao facto daquela expressão não comportar um uso neutro, pois que para se referir à humanidade a palavra Homem teria de ser iniciada com letra maiúscula. Isto não obstante mais adiante, no artigo 7.o, o legislador, num acesso de neutralidade e a propósito do dever de igualdade da lei, expressar que a lei civil é igual para todos, não fazendo distinção de pessoas. Cremos que o contraste destas duas expressões se torna eloquente: o uso indistinto dos termos «homem»e «pessoas» para fazer referência à universalidade do direito; e o facto de a lei somente especificar o sexo quando se trata de mulheres, indicam- nos que os direitos, na sua gênese, são masculinos e demonstram-nos como, no discurso jurídico, a mulher foi historicamente construída como «o Outro» (SOUSA, 2014, p. 12-13).

O Feminismo, enquanto "toda teoria, pensamento e prática social, política e jurídica que tem por objetivo tornar evidente e terminar com a situação de opressão que as mulheres suportam e assim alcançar uma socidade mais justa" (RICOY, 2015, p. 468, tradução nossa) ${ }^{1}$, dentre outras demandas, possui papel central no questionamento da ordem jurídica vigente por conta da representacão que dá as mulheres - esteriotipada e discriminatória — deixando de garantir-lhes a igualdade plena e efetiva.

A Teoria Feminista do Direito teve seu desenvolvimento praticamente ligado às correntes do Feminismo norte-americano, como a liberal, marxista, radical e a pós-moderna, de modo que não se pode tecnicamente falar em uma única Teoria Feminista do Direito ou mesmo em uma teoria universal - o que fazemos apenas didaticamente, utilizando letras maiúsculas para identificá-la enquanto gênero -, pois, assim como o movimento feminista, há divergências significativas que não permitem a homogeneização.

De modo geral, tais teorias surgiram com o objetivo comum de integrar completamente seu arcabouço teórico, criado a partir do ponto de vista feminino, com as práticas políticas, de modo a modificar efetivamente a estrutura jurídica e, consequentemente, a realidade social

1 “(...) toda teoría, pensamiento y práctica social, política y jurídica que tiene por objetivo hacer evidente y terminar con la situación de opresión que soportan las mujeres y lograr así una sociedad más justa” (RICOY, 2015, p. 468) 
existente, que era considerada discriminatória e opressora para com as mulheres, reconceitualizando a noção de justiça (SMART, 2002).

Adiante, abordaremos as ondas do movimento feminista norteamericano, no intuito de contextualizar algumas das principais teorias feministas do Direito, que igualmente serão tratadas neste estudo.

\subsection{FASES DAS TEORIAS FEMINISTAS DO DIREITO E ONDAS DO} FEMINISMO

De acordo com Barnett (1998) a primeira fase da Teoria Feminista do Direito foi dos anos de 1960 a 1980 e seu escopo era identificar as características do Direito que excluíam as mulheres da vida pública. A principal questão levantada aqui era o debate acerca da igualdade entre homens e mulheres em todos os aspectos da vida, incluindo o emprego, a política e a educação. Não havia a preocupação em questionar o sistema jurídico como um todo, mas tão somente uma visão reducionista focada em modificar as leis para diminuir as desigualdades.

Na primeira onda do Feminismo, o movimento buscava mostrar que as mulheres eram igualmente capazes em relação aos homens, especialmente quanto ao trabalho e educação, e por isso deveriam ter os mesmos direitos e obrigações que eles. $\mathrm{O}$ discurso era pautado na igualdade de capacidades naturais, direitos e liberdades.

A segunda fase das teorias feministas teria ocorrido nas décadas de 1970 e 1980, no auge do movimento hippie, e questionava agora o sistema jurídico em si como mecanismo de manutenção das desigualdades entre os sexos, de forma que não bastaria a mudança nas leis, sendo necessária mudança no discurso jurídico (BARNETT, 1998). Coincidiu com a segunda onda do Feminismo no que tange a afirmação da existência de um sistema cultural de opressão específica que impediria a igualdade feminina na prática, o que chamamos hoje de patriarcado.

A terceira fase das teorias feministas, ocorrida durante o período de 1980 e 1990, passa a enxergar o Direito como um fenômeno complexo que não é exclusivamente masculino (BARNETT, 1998). Aqui, tal qual a terceira onda do movimento Feminista, há ênfase nas diferenças entre as próprias mulheres, com a compreensão de que não se pode homogeneizálas nem quando se busca avanços, pois suas necessidades são distintas a depender de raça, idade, classe social, intersexualidade, dentre outros fatores. 
No Brasil e na América Latina as demandas femininas e os períodos nos quais ocorreram são distintas das existentes nos Estados Unidos e, consequentemente, também é diferente a relação entre mulher e Direito. Tem-se na América Latina pautas específicas como a luta contra a colonização das mulheres indígenas, das mulheres contra a ditadura militar brasileira, das quilombolas, das mulheres negras amazônidas e outras que são resultado de contextos históricos diversos, com fatos sociais típicos desses países.

\subsection{CORRENTES DA(S) TEORIA(S) FEMINISTA(S) DO DIREITO}

Assim como o Feminismo possui “ondas" que representam os momentos históricos e as ideologias que vivenciou com o passar do tempo, também a Teoria Feminista do Direito possui variadas correntes, entretanto, não se trata de uma classificação rígida, mas tão somente de diferentes ênfases temáticas que variaram conforme o entendimento e o contexto sóciopolítico de cada época.

Escolhemos algumas destas correntes para, sinteticamente, ilustrar a diversidade entre elas e suas contribuições para a modificação do paradigma científico jurídico da modernidade.

\subsubsection{LIBERAL}

A teoria feminista liberal é também conhecida como feminismo da igualdade ou igualitário, tendo em vista a igualdade de direitos civis e políticos ser a principal reivindicação da mesma. Para esta corrente era primordial que o Direito refletisse a total igualdade entre homens e mulheres a fim de que, paulatinamente, a sociedade fosse sendo modificada neste aspecto.

De acordo com Sousa (2014, p. 20), “o feminismo liberal teve como objetivo lato o de abrir o acesso às mulheres a àreas (sic) da vida até então exclusivas dos homens", uma vez que acreditava que a maior fonte de opressão das mulheres era a desigualdade entre eles, nitidamente refletida no espaço público.

As feministas liberais, como Betty Fiedan, acreditavam que enfatizar as semelhanças entre homens e mulheres seria o caminho a ser percorrido na busca pelo aperfeiçoamento gradual das instituições, o que ocorreria por meio de reformas legislativas (CAIN, 1989). 
Anna Marcella Mendes Garcia \& Camyla Galeão de Azevedo

\subsubsection{RADICAL}

Segundo Heloisa Buarque de Holanda (2018), o feminismo radical surgiu na segunda onda do movimento feminista, por volta da década de 1960, e levantou a questão de que o patriarcado é um sistema que atravessa a história das civilizações, sendo anterior e a raiz dos outros sistemas de opressão. Segundo a autora:

O feminismo radical vê o patriarcado como um sistema de poder no qual o homem se encontra em posição de superioridade em relação à mulher e é detentor do poderio econômico. A divisão entre os sexos cria uma dicotomia social em que o homem tem autoridade sobre a vida, as escolhas e o destino das mulheres, o que provoca uma divisão que a chamamos de casta sexual. A ferramenta social para manter a mulher oprimida é o sexismo, o que enfatiza o privilégio masculino, base das relações sociais (HOLANDA, 2018, p. 400).

O feminismo radical se organiza de tal maneira para a defesa da abolição do conceito de gênero, já que impõe à mulher papéis estereotipados, a partir de marcadores sociais, não naturais, que formam o ser enquanto feminino, como roupas, calçados e acessórios, sendo diferente, portanto, o comportamento de um homem e de uma mulher, já que são resultados de diferentes tipos de socializações. Como consequência da crítica ao gênero, o feminismo radical não apoia e não se filia a transgeneridade, embora hajam feministas radicais que apoiem os direitos dos transexuais (HOLLANDA, 2018).

Partindo desse pressuposto, o feminismo radical se organiza como um movimento político e social que busca a emancipação das mulheres através de sua condição de subalternidade. Ao contrário do que o sendo comum pensa sobre o feminismo radical, não prega ódio aos homens, mas a rejeição do machismo e do patriarcado.

A teoria radical discorda da liberal no que tange à busca pela igualdade. As adeptas a essa teoria, como Catharine MacKinnon, aduzem que estabelecer este objetivo é confirmar que as normas são originariamente masculinas e tentar adequar-se a elas, enquanto que o correto seria o contrário. Para tanto, o foco deveriam ser as relações de poder historicamente consolidadas entre homens e mulheres, de modo a prejudicá-las e oprimi-las.

Para esta teoria as mulheres devem ser vistas enquanto classe que historicamente é oprimida por outra, e não individualmente, como no feminismo liberal. É negada a noção de uma natureza ou essência feminina, partindo-se da concepção de que o "feminino" é socialmente construído, então não haveria uma diferença inata entre os sexos, a não ser a biológica. 
Seria, portanto, "a dominação, e não a diferença, que subalterniza as mulheres, e portanto o foco da análise é correctamente (sic) colocado na dominação: a questão a colocar não é se a lei gera desigualdade para as mulheres, mas se a lei gera dominação para as mulheres" (SOUSA, 2014, p. 38-39). A lei perpetua a dominação na medida em que garante mais poder aos homens, o que deve ser combatido.

\subsubsection{DA DIFERENÇA OU CULTURAL}

O feminismo da diferença ou cultural surgiu como uma crítica ao feminismo da igualdade - que sustentava a igualdade entre os sexos de maneira generalista - por entender que se tratava de uma concepção reducionista, que homogeneizava as mulheres, e ainda assim mantinha a dominação masculina.

As feministas pertencentes a esta corrente defendem que há diferenças substanciais na experiência de vida das mulheres que não permitem tratá-las de forma uniforme entre si, tampouco em relação aos homens, o que deve ser assimilado pelo Direito. Um exemplo deste pensamento é o direito das mulheres ao voto não como fruto de sua igualdade em relação aos homens, e sim de suas diferenças, que torna necessária sua representatividade eleitoral.

De acordo com Rosa Ricoy, são expoentes desta corrente Kate Millet com a obra Política Sexual e Sulamith Firestone, com La dialéctica de la sexualidad.

\subsubsection{DECOLONIAL}

Esta teoria examina não só o referencial masculino, mas também norte-americano, questionando as próprias teorias feministas anteriores. Isto porque o contexto social, político e econômico da América Latina é completamente diferente do norte-americano, não podendo este servir como referência para as experiências de vida das mulheres latinas.

A teoria feminista decolonial alerta para não só para a opressão das mulheres em relação aos homens, mas também dos países subdesenvolvidos “às forças econômicas multinacionais, da relação centro-periferia e como a modernização e a globalização afetam as mulheres destes países” (KULKAMP, 2017, p. 10). 
Essa corrente, especificamente, propõe a desconstrução dos feminismos ocidentais hegemômicos e a criação de estratégias para impulsionar os feminismos do sul-global, ou de terceiro mundo, mais atentos à heterogeneidade das mulheres e suas especificidades (MOHANTY, 1991, p. 1)

São expoentes desta corrente Maria Lugones e Rita Segato; ambas destacam que as opressões sofridas pelas mulheres latino-americanas advém não somente do patriarcado, mas também do sistema colonial moderno que afeta todas as esferas da vida das mulheres. Dentro desta corrente não se olvidam as diferenças e interseccionalidades existentes entre as mulheres de um mesmo país e/ou de vários, não caindo na armadilha reducionista outrora vigente no Feminismo. Pode ser considerada uma subcorrente do feminismo pós-moderno, que aborda as diferenças entre as mulheres, e não somente destas em relação aos homens.

\section{A NECESSIDAdE DA PRODUÇÃO E ENSINO DE TEORIA(S) FEMINISTA(S) DO DIREITO}

O Direito enquanto ciência, supostamente, tem suas bases fincadas na neutralidade política e ideológica, o que garantiria a isonomia entre os indivíduos, e na objetividade, para que assim possa autodeclarar-se de aplicabilidade universal. Ocorre que não é possível falar em neutralidade científica quando os pesquisadores e, neste caso específico os legisladores, historicamente pertencem em sua maioria a um único sexo, uma única raça e uma única classe social, salvo raras exceções que tornaram-se mais frequentes na contemporaneidade.

A ausência de neutralidade científica no direito decorre da atribuição histórica de determinados papéis aos homens e as mulheres. Eles são considerados seres naturalmente culturais, com o instinto político e cultural. As mulheres são consideradas muito mais próximas de sua natureza, pois por possuírem condições biológicas diferenciadas, como o ato de procriar e amamentar, são destinadas ao espaço privado (PATEMAN, 2018).

$\mathrm{Na}$ atualidade, a esfera pública seria espaço para a universalidade, razão e impessoalidade. Não é espaço para emoções e sentimentos. Já a esfera privada, seria espaço das relações envolvendo o caráter pessoal e íntimo. Na esfera pública os indivíduos são definidos como manifestações da humanidade ou de cidadania comum a todos. Na esfera privada, os indivíduos se apresentam em suas individualidades concretas e particulares. 
A partir dessa divisão clássica entre os espaços, surge a criação de estereótipos de gênero, promovendo consequências negativas até os dias de hoje para as mulheres. Naturalmente, desde o período clássico, atribui-se papéis a elas, como a dedicação prioritária ao âmbito privado, à vida doméstica e aos familiares, colaborando para que a domesticidade feminina fosse vista como algo natural e distintivo, bem como um valor. Aos homens, ainda são atribuídos papéis relacionados à vida pública. A vinculação da mulher ao espaço privado acaba por provocar consequências que vão muito além desse espaço, provocando reflexos para o âmbito público.

Uma das consequências proveniente da atribuição do âmbito privado para as mulheres personifica-se através da divisão sexual do trabalho, promovendo a baixa participação das mulheres na política. A posição das mulheres nas relações de trabalho está no cerne das formas de exploração que caracterizam a dominação de gênero ou a própria presença do patriarcado. Nesta seara, afirma-se que a distinção entre trabalho remunerado e não remunerado é um ponto central dentro da separação entre espaços de poder.

Por serem naturais do âmbito privado desde a era clássica, o trabalho que as mulheres naturalmente exercem é sem remuneração, como aquele que está implicado na criação com os filhos, no cuidado de idosos, na realização de atividades domésticas, concedendo total abertura para que os homens se engajem em trabalhos remunerados e políticos. Segundo Flávia Biroli (2018) "são elas apenas que fornecem esse tipo de trabalho gratuitamente, e essa gratuidade se define numa relação: o casamento. É nele que o trabalho gratuito das mulheres pode ser caracterizado como não produtivo" (BIROLI, 2018, p. 28).

O censo do Instituto Brasileiro de Geografia e Estatística (IBGE) demonstrou que, em dez anos, o nível de instrução das mulheres continuou mais elevado que o nível dos homens. No ano de 2000, as mulheres já eram a maioria no ensino superior. Novas pesquisas do IBGE mostram, ainda, que entre os vinte maiores cursos universitários, as mulheres não se fazem presentes apenas em cinco deles, são eles: ciência da computação, engenharia civil, engenharias, economias e cursos gerais de saúde. O curso de direito, segundo o mesmo censo, é formado $55 \%$ por mulheres (O GLOBO, online, 2013).

Segundo Heloisa Buarque de Hollanda (2018), numa pesquisa preliminar realizada nos diretórios de grupos de pesquisa registrados no CNPQ (Conselho Nacional de Desenvolvimento Científico e Tecnológico), há quase trezentos grupos que envolvem debates sobre gênero, sob as denominações mais diversas. Todos os Estados Brasileiros possuem, pelo menos, um grupo 
de pesquisa. Esses grupos se concentram mais na região Nordeste. O Nordeste é a região com maior número de grupos que interseccionam raça, gênero e diversidade sexual (HOLLANDA, 2018).

A partir dessa perspectiva, há uma forte discussão também sobre a inserção do gênero no currículo de escolas e universidades. O III Plano Nacional de Políticas para as Mulheres (PNPM), de 2013 a 2015, definiu, entre as suas estratégias de ação a criação de Diretrizes Curriculares Nacionais específicas de gênero que contemplem as abordagens de classe social, raça, etnia, orientação sexual e geracional para todos os níveis, etapas e modalidades de ensino. Entretanto, com a desestabilização da política, com o impeachment de Dilma Roussef, o Conselho Nacional de Direitos da Mulher sofreu um retrocesso, ocasionando a perda de seu status de Ministério (HOLLANDA, 2018).

Além da perda do status de Ministério, verifica-se que, em 2017, o Ministério da Educação enviou a Base Nacional Comum Curricular ao Conselho Nacional de Educação, pela qual retira do documento as menções de gênero e orientação sexual e tornou sua inclusão restrita a iniciativas de professores ou em articulações pontuais de alguns cursos universitários.

Apesar de já existirem diversos grupos de pesquisa espalhados pelo Brasil, o cenário dos estudos de gênero nas universidades brasileiras ainda é contraditório. Há um empenho significativo na institucionalização desses estudos, entretanto, o "prestígio de gênero ainda é visivelmente baixo. Muitas das vezes o gênero é considerado uma subespecialidade dentro de áreas mais amplas, e não uma questão epistemológica que coloca em suspensão a própria ideia de "campos de conhecimento"”. (HOLLANDA, 2018, p. 209).

No âmbito da formação do quadro das universidades brasileiras, é inegável que houve um aumento de mulheres, profissionais, estudantes e técnicas na formação das universidades brasileiras. Segundo dados apresentados por Hollanda (2018), 73\% nos últimos dez anos, perfazendo, no caso das estudantes mulheres, 55,6\% dos 8033574 matriculados nas universidades brasileiras, segundo censo escolar de 2015.

Entretanto, mesmo as mulheres sendo a maioria no corpo estudantil e técnicoadministrativo e estejam bem representadas enquanto corpo docentes e pesquisadoras, quando se fala da assunção de cargos de prestígios e de poder, a situação muda. Como exemplo, podese citar a subpresença das mulheres na chefia máxima das instituições federais de ensino superior: em 2016, apenas um terço havia uma reitora mulher (HOLLANDA, 2018). 
Entretanto, por mais que as mulheres possuam maior nível de conhecimento, compondo mais da metade do público do curso de Direito, as bases da ciência jurídica ainda são pautadas em questões androcêntricas.

A necessidade de se pensar o Direito sob novas perspectivas é reivindicada por diversas teorias, algumas originárias de movimentos sociais protagonizados por grupos excluídos do poder, como mulheres, pessoas com deficiência, negros, dentre outros. Tais grupos tem em comum o prejuízo advindo das concepções masculinas tradicionalmente vigentes no Direito, as quais tipificaram estes indivíduos a partir da visão do homem branco burguês, o que os relegou a um posto marginal dentro da sociedade, no qual suas demandas específicas costumam ser silenciadas.

Entende-se aqui como teorias tradicionais do Direito aquelas que partem do olhar masculino para teorizar e/ou regular a realidade social, dentre as quais encontram-se o jusnaturalismo, juspositivismo, análise econômica do Direito, teorias hermenêuticas, dentre outras, cuja convergência se dá no fato de que foram produzidas em sua maioria por homens brancos, questionando o que lhes era pertinente e olvidando as demandas femininas, já que as mulheres não possuíam representatividade neste cenário.

Ainda que diversas, as teorias acima citadas foram aceitas pela comunidade acadêmica durante décadas e, quando questionadas, o eram apenas contrapondo-se outras teorias pautadas na mesma visão masculina. São elas que norteiam questões de extrema relevância como "O que é Direito?”, “O que é Justiça?”, “Para que serve o Direito?”, dentre outras tidas como universais. Acontece que estas teorias são limitadas, tendo em vista que partem de uma única visão de mundo - do homem branco da elite -, deixando de refletir acerca de questões igualmente importantes, mas que partem de visões minoritárias advindas de outra realidade social, como “A quem serve o Direito?".

O pensamento masculino é o pilar não somente da teoria, mas também e por consequência da prática jurídica, de forma que "o esteriótipo social do masculino e do feminino se veem também refletidos e inclusive reforçados pela atuação dos Tribunais" (RICOY, 2015, p. 460 , tradução nossa) $)^{2}$. Esta influência é ainda mais nítida nos processos envolvendo questões de gênero, como violência sexual, nos quais absurdamente se questiona a conduta da vítima,

2 “el esteriotipo social de lo masculino y lo femenino se ven también reflejados e incluso reforzados por la actuación de los Tribunales” (RICOY, 2015, p. 460) 
"revitimizando-a" por meio das discriminações sofridas por parte dos agentes estatais no curso processual.

As críticas formuladas pelas teorias jurídicas feministas direcionam-se para as teorias ditas tradicionais no que tange particularmente à conceituação que estas dão ao Direito e ao sistema jurídico como um todo a partir de uma visão androcêntrica universal, reforçando as relações de já poder existentes e, consequentemente, reproduzindo discriminações a determinados grupos, como as mulheres.

O maior equívoco das teorias tradicionais, para as teorias feministas, seria, portanto, o fato de que elas partem da premissa de que mulheres e homens são iguais enquanto sujeitos de direitos, uma vez que a lei, por ser derivada da racionalidade, seria aplicada indistintamente para ambos, o que supostamente a tornaria neutra no que tange ao gênero, o que não condiz com a realidade.

Carol Smart (2002) destaca que a Teoria Feminista do Direito não visa somente uma reforma nas leis, e sim assinala a necessidade de uma mudança paradigmática nesta área, ou melhor, "sinaliza a mudança de uma concentração na reforma legal e 'adição de mulheres' em considerações legais à preocupação com questões fundamentais como lógica legal, valores legais, justiça, neutralidade e objetividade" (SMART, 2002, p. 66, tradução nossa) ${ }^{3}$.

As teorias feministas são exitosas ao expor a concepção objetivista e tecnicista das teorias tradicionais do Direito, pautadas somente na validade deste. Kulkamp (2017, p. 12) assevera:

Estas críticas, entre outras não expostas aqui, revelam como as teorias tradicionais estão mais preocupadas com a validade do direito do que com seus efeitos sobre os indivíduos (BARNETT, 1998). Efeitos estes, que excluíram as mulheres do âmbito do direito ou as colocaram como "representadas" sobre o domínio masculino, o que não explica as profundas desigualdades econômicas, políticas, sociais entre mulheres e homens existentes na sociedade.

Neste cenário discriminatório destaca-se a questão do gênero enquanto construção social que padroniza os comportamentos individuais de acordo com representações idealizadas

\footnotetext{
3 "The search for a feminist jurisprudence signals the shift away from a concentration on law reform and 'adding women' into legal considerations to a concern with fundamental issues like legal logic, legal values, justice, neutrality, and objectivity" (SMART, 2002, p. 66).
} 
dividas de acordo com o sexo biológico dos indivíduos, isto é, estipula condutas ditas femininas ou masculinas.

As mulheres são retratadas e tuteladas no ordenamento jurídico a partir da visão masculina, ou seja, de acordo com os padrões estipulados por uma ordem social sexualmente baseada com concepções próprias ao modo como a mulher deve ser, agir, se comportar, enfim, viver.

As teorias feministas do Direito — ou feminist jurisprudence, termo americano utilizado pela primeira vez em 1978, em uma conferência de advogadas feministas em Harvard (CAIN, 1989) - questionam a posição de sujeito central que o homem ocupa neste ramo do saber, destacando que, por conta deste protagonismo exclusivamente masculino, a mulher tinha seus problemas, especificidades e demandas invisibilizados. Tais teorias despertam para os fatos de que não há neutralidade dentro da ciência do Direito e de que este pode e deve ser compreendido não somente sob o viés político, mas também sexual.

As teorias jurídicas feministas trazem, então, questionamentos a serem pensados fora da lógica hegemônica masculina, como, por exemplo, "Qual o papel da mulher dentro da teoria do Direito?", “O Direito garante a isonomia de fato ou somente reflete o poder e a autoridade masculina?" ou "O Direito contribui para a minimização da desigualdade social, política e econômica das mulheres ou ao contrário, é um meio para sua manutenção?”. Tais questionamentos exigem uma análise crítica do Direito sob a perspectiva feminista, isto é, partindo do olhar daquele que até então era considerado "o Outro."

\section{CONSIDERAÇÕES FINAIS}

Via de regra, todos os ordenamentos jurídicos ocidentais tiveram o homem como legislador e, consequentemente, sofreram a influência direta de sua visão de mundo. Ocorre que estas sociedades são, senão em sua totalidade, majoritariamente patriarcais e misóginas, o que, por óbvio, reflete em seu Direito. Isto porque não há como se falar na prática em neutralidade científica, uma vez que o sujeito acaba por interferir, ainda que minimamente, no conhecimento científico por ele produzido.

Não foi diferente com o ordenamento jurídico brasileiro, o qual desde sua gênese tratou a mulher como subordinada aos homens, inicialmente ao seu pai e, posteriormente, ao 
seu marido; tanto é assim que o hoje conhecido poder familiar por muitas décadas foi chamado de pátrio poder, isto é, o poder do homem sobre os membros da família.

O Direito tem, portanto, a desilgualdade incrustrada em natureza e, desta feita, acaba por tornar-se um mecanismo de discriminação, pois:

(...) o Direito não escapou da circunstância do sexismo, pois coaduna de modo importante na manutenção de semelhante realidade discriminatória, até o ponto de considerar que os princípios e procedimentos que se consideram garantia e expressão da racionalidade prática, talvez não sejam mais do que uma manifestação da perspectiva do homem, cuja universalização seria uma maneira de silenciar a perspectiva das mulheres. (RICOY, 2015, p. 459, tradução nossa) ${ }^{4}$

Em decorrência do acesso tardio à educação jurídica, a produção acadêmica feminina era pequena se comparada a dos homens, o que já não se pode dizer na atualidade, em que as mulheres são responsáveis por $72 \%$ (setenta e dois por cento) da produção científica brasileira ${ }^{5}$, entretanto, ainda se ensinam na Academia teorias que as excluem e não consideram suas especificidades.

Apesar de todo o avanço político, educacional, social e econômico atingido pelas mulheres por meio das lutas feministas, as produções com este teor ainda são vistas com desdém e incredulidade pela Academia, especialmente no sul global, onde este debate é relativamente mais recente, diferente dos Estados Unidos, por exemplo.

A falta de debate sobre o tema, inclusive na Academia, afeta negativamente o exercício pleno da cidadania pelas mulheres, as quais foram e continuam sendo associadas ao privado, enquanto que os homens pertencem ao público/político, naturalizando sua opressão e inferiorização.

A centralidade do Direito estar fincada no olhar masculino faz com que as mulheres sejam meras coadjuvantes tanto na teorização da ciência jurídica quanto em sua prática social.

\footnotetext{
4 (...) el Derecho no ha escapado a la circunstancia del sexismo, pues coadyuna de modo importante en el mantenimiento de semejante realidad discriminatoria, hasta el punto de considerar que los principios y procedimientos que se consideran garantía y expresión de la racionalidad práctica, tal vez no sean más que una manifestación de la perspectiva del hombre, cuya universalización sería una manera de silenciar la perspectiva de las mujeres. (RICOY, 2015, p. 459)
}

5 Para mais, consultar: https://oei.org.br/noticia/estudo-da-oei-aponta-conquista-das-mulheres-do-meiocientifico-no-brasil. 
Isto faz com que a visão que o ordenamento jurídico reflete da mulher seja esteriotipada e porque não inferiorizada, já que ela não teve voz na construção do mesmo. Esta visão deturpada por óbvio acarreta graves prejuízos às mulheres, que não se veem devidamente representadas.

Carol Smart (2002) alerta para o fato de que o ensino jurídico na verdade nada mais é do que "a inculcação da lógica 'masculina' e do argumento que não apenas nega a validade de construções alternativas, mas também representa o único método objetivo e neutro" (SMART, 2002, p. 67, tradução nossa) ${ }^{6}$.

As teorias feministas do Direito procuram romper os paradigmas dominantes na ciência jurídica e colocar as mulheres em patamar de igualdade em relação aos homens, sem, no entanto, olvidar suas especificidades, permitindo que ambos atuem na esfera pública, o que inclui a produção do conhecimento jurídico.

Rosa Ricoy (2015) destaca que "enquanto não se superar este muro jurídico, as mulheres não serão cidadãs, se por isto se entende aqueles sujeitos no exercício completo de seus direitos políticos, econômicos e civis" (RICOY, 2015, p. 462, tradução nossa) ${ }^{7}$.

Tais teorias possuem a capacidade de modificar a visão que se tem das mulheres dentro do Direito, seja na Academia ou no próprio ordenamento jurídico, afetando sobremaneira várias esferas de sua vida, rompendo com desigualdades e opressões historicamente consolidadas.

Ademais, a complexidade e multiplicidade das correntes que compõem a Teoria Feminista do Direito como um todo permite uma releitura e um rearranjo estrutural no Direito capazes de torná-lo condizente com a diversidade de mulheres que há em nossa sociedade, de modo a torná-lo igualitário e inclusivo não só em um aspecto intergênero, mas, também, intragênero, o qual não pode ser desconsiderado a quando da busca por uma sociedade verdadeiramente justa.

Ante o exposto, defende-se que as teorias jurídicas feministas devem ser amplamente difundidas nos cursos de Direito, pois são as mais hábeis a modificar as estruturas opressoras e discriminatórias existentes no ordenamento jurídico, formando profissionais capazes de pensar criticamente e até mesmo modificar a ordem jurídica vigente na sociedade brasileira.

\footnotetext{
6 “(...)the inculcation of 'male' logic and argument which not only denies the validity of alternative constructions, but also poses as the only objective and neutral method" (SMART, 2002, p. 67).

7 "mientras no se supere este muro jurídico, las mujeres no seran ciudadanas, si por tal se entiende aquellos sujetos en el ejercicio completo de sus derechos políticos, económicos y civiles” (RICOY, 2015, p. 462).
} 
Anna Marcella Mendes Garcia \& Camyla Galeão de Azevedo

\section{REFERÊNCIAS}

BARNETT, Hilarie. Introduction to feminist jurisprudence. London: Cavendish Publishing Limited, 1998.

BEAUVOIR, Simone de. O segundo sexo. São Paulo: Difusão Européia do livro, 1970.

BIROLI, Flávia. Divisão Sexual do Trabalho e Democracia. Rio de Janeiro: Revista de Ciências Sociais, vol. 59, $\mathrm{n}^{\mathrm{o}}$ 3, 2016. Disponível em: http://dx.doi.org/10.1590/00115258201690. Acesso em: 15 dez. 2018.

BIROLI, Flávia. Gênero e Desigualdades: os limites da democracia no Brasil. São Paulo: Boitempo, 2018.

CAIN, Patricia A. Feminist jurisprudence: grounding the theories. 4 Berkeley Women's L.J. 191, 1989. Disponível em: https://scholarship.law.berkeley.edu/bglj/vol4/iss2/1/. Acesso em 07 ago. 2018.

HOLLANDA, Heloisa Buarque de. Explosão Feminista: arte, cultura, política e universidade. São Paulo: Companhia das Letras, 2018.

KULKAMP, Camila. Apontamentos introdutórios sobre as teorias feministas do direito. V Fórum Brasileiro de Pós-graduação em Ciência Política "Caminhos da Democracia no Brasil". Disponível em http://www.forumcienciapolitica.com.br/anais2017/pdfs/plenary/BRMQ.pdf. Acesso em 09 ago. 2018.

MIGUEL, Luis Felipe. Dominação e Resistência: desafios para uma política emancipatória. São Paulo: Boitempo, 2018.

MIGUEL, Luis Felipe; BIROLI, Flávia. Feminismo e Política: uma introdução. São Paulo: Boitempo, 2014.

MOHANTY, Chandra Talpade. Third world women and the politics of feminism. Bloomington: Indiana UP, 1991.

OEI. Estudo da OEI aponta conquista das mulheres do meio científico no Brasil. Disponível em: https://oei.org.br/noticia/estudo-da-oei-aponta-conquista-das-mulheres-domeio-cientifico-no-brasil. Acesso em 04 abr. 2019.

O GLOBO. Mulheres são a minoria em apenas cinco carreiras. Disponível em: https://oglobo.globo.com/economia/emprego/mulheres-sao-minoria-em-apenas-cincocarreiras-7216998. Acesso em: 31 mar. 2019.

PATEMAN, Carole. O Contrato Sexual. São Paulo: Paz e Terra, 1993 
PATEMAN, Carole. EI Desorden de Las Mujeres: democracia, feminismo y teoría política. 1 ed. Ciudad Autonoma de Buenos Aires: Prometeo Libros, 2018.

RICOY, Rosa. Teorías jurídicas feministas. In ZAMORA, Jorge Luis Fabra; VAQUERO, Álvaro Núñez (editores). Enciclopedia de Filosofía y teoría del derecho. México: UNAM, Instituto de Investigaciones Jurídicas, 2015.

SMART, Carol. Feminism and the power of law. London: Taylor \& Francis e-Library, 2002.

SOUSA, Rita Alexandra Bareira da Mota de. Teorias feministas do direito: a emancipação do direito pela mulher. Rio de Janeiro: PUC, Departamento de Direito, 2014. 